\section{Denis Cain}

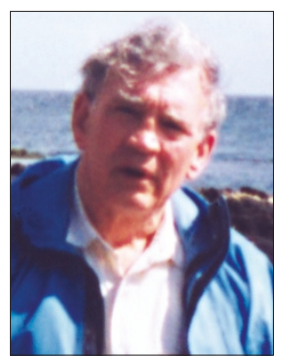

It is with great sadness that I record the death from cancer of Denis Cain at the age of 76.

Born in 1928 in Salford, Denis and his family moved to Birmingham where he was educated. After completing National Service, he re-enlisted with the East Kent Regiment (The Buffs) and enjoyed a meteoric rise through the ranks to become the youngest colour sergeant in the country at the time. During his six-year regular army career he travelled extensively, notably to Aden and also Germany, where he met his wife, Gisela. They married and produced a son, Stephen.

At this time, Denis decided that in order to provide a more stable environment for his son he must leave the army. His uncle, a GDP in Manchester, offered him the possibility of taking over his practice. The fact that Denis decided, at age 34, to set out on this road and successfully gained a degree in dentistry, says much about his forthright, determined character.

In 1962 I first met Denis as a fellow student at Birmingham Dental School. He cut a striking figure amongst our group of 35, not least because he was 16 years older than most of us. Despite this, his friendly countenance and life experience endeared him to us all during the arduous, but happy, years of study.

Qualifying in 1966, Denis took over his uncle's practice and, with hard graft, created a first class multi-surgery practice, supported by Gisela, who managed to combine being a wife and mother with working in virtually every capacity from decorator to surgery assistant to receptionist.

The arrival of his newly qualified son in the practice enabled Denis to do something completely different. Ever the adventurer and always relishing a challenge, he bought a gypsy caravan and a horse named Prince and spent a year exploring Britain, bringing a

\section{... a man with an innate sense of duty}

\section{and a genuine concern for others.}

different meaning to the concept of the mobile dental caravan! Denis also loved to walk, and was never happier then when walking the fells of the Lake District.

Denis's interests and talents were wide ranging; he could be described as a true polymath. His intelligence and impressive memory enabled him to talk with authority on a wide range of subjects. Not many people achieve an honours degree in Humanities from the Open University at age 67. These qualities, together with a wicked sense of humour, made him brilliant company.

Denis retired from practice 17 years ago and spent a very happy retirement on the Isle of Man, the ancestral home of the Cains. He managed to walk all over the island; indeed it is probable that few native Manxmen will have explored it as thoroughly as he did.

Denis was a very compassionate man with an innate sense of duty and a genuine concern for others. He cared for his parents in their final years and brought his ageing aunt and uncle to live within the family home on the island when they were too old to look after themselves. In more recent years, he was also a caseworker for SAAFA - an organisation helping ex-service people in need.

I am sure that I speak for his many friends, acquaintances and former colleagues when I say that it was a great privilege to have known Denis and that they would all wish to join with me and express sympathy to Gisela, Stephen and the family in their sad loss.

P. Hill

\title{
Colin Poggo
}

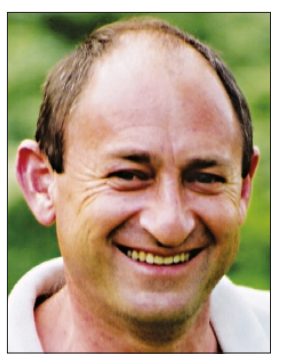

Colin Poggo died on Friday 8 October 2004 after a 19 month battle against pancreatic cancer. He was 51 . He fought this terrible disease with the same optimism and good humour with which he lived his life.

Colin qualified as a doctor in 1978 from Witwatersrand University, Johannesburg and came over to the UK in 1982. He began doing dental anaesthetics full time in 1987 when he visited surgeries with his mobile unit. In 1990 he realised that in order to provide dental anaesthetics more safely and efficiently there was a need to have fully equipped clinics with properly trained staff that patients could be referred to for their treatment. He went into partnership with over 40 dentists during the 1990s and his company became the biggest provider of dental anaesthetics in the country. During these times he was a controversial figure as many people felt that dental anaesthetics should only be provided in hospitals, but he proved that there was a real need for referral centres as hospital waiting lists became longer. The success of the clinics showed that they were held in high regard by referring dentists.

The change in regulations in 1998 hit the company hard, but it managed to adapt and showed that it is in fact possible to treat the

\section{Both patients and staff could not help but be infected by his good nature, humour and love of life.}

vast majority of cases under intravenous sedation and relative analgesia. In 2001, with two other dentists, Colin started First Choice Dental which now has a number of practices specialising in sedation.

Although Colin did not do a lot of anaesthesia himself in the last few years as he took on an administrative role, anyone who has worked with him knows that he was an excellent anaesthetist himself. Both patients and staff could not help but be infected by his good nature, humour and love of life.

Sadly, Colin leaves wife Ellen and their two children, Natalie and Ross, and Lauren, his daughter from his first marriage to Pauline. Our thoughts are with them at this time and all of us who knew Colin lament the passing of a true and loyal friend. 